\title{
Analysis of the Aspen Growth (Populus tremula L.) Obtained by in Vitro in the Republic of Tatarstan
}

\author{
Guzel Petrova*, Aigul Mukhametshina, Haris Musin and Renat Gafiyatov
}

Kazan State Agrarian University, Kazan, 420015, Russia

\begin{abstract}
The paper presents the results of an experiment on the propagation of aspen clones (Populus tremula L.) of diploid and triploid genotypes resistant to pith rot by methods of microclonal reproduction and their introduction into forestry production in the Republic of Tatarstan. The expediency of using this method for obtaining healthy aspen planting material has been substantiated, and the prospects for the reproduction of clone No. 35 with a triploid genotype have been shown.
\end{abstract}

\section{Introduction}

Aspen (Populus tremula L.) is one of the fastest-growing tree species, and healthy aspen wood is highly valued. It is distributed throughout Russia and is adapted to forest conditions. This breed is unpretentious and grows on medium-fertile soils, resistant to frost [1]. Studies have shown that healthy aspen has many valuable forestry and economic properties; it can be effectively used as a thermal energy source. Unfortunately, aspen tends to be affected by fungal diseases that cause pith rot of the trunks, which leads to a decrease in the quality of wood [4-6]. However, in the republic, there are highly productive clones resistant to fungal diseases. Therefore, today the most important task of foresters is the creation and cultivation of healthy and highly productive aspen plantations [2, 3]. How to ensure that business aspen can be harvested in sufficient volumes and at the same time receive income to budgets of different levels? This question has been pondered for a long time. Traditional methods of vegetative propagation are not always successful.

Currently, a promising alternative to traditional breeding methods is cell biotechnology [7]. For the reproduction of aspen on an industrial scale and preserving its biodiversity, the technologies of clonal micropropagation are used - by asexual means under "in vitro" conditions. This method allows for the propagation of plants that are difficult to propagate or do not propagate at all by traditional vegetative methods. An important advantage of micropropagation is the reduction in the duration of the breeding process. In addition, the quality of the planting material of woody plants can be improved due to its health improvement and selective reproduction of only the best genotypes [8]. It is very important to use valuable specimens as starting material.

There are many methods for clonal micropropagation. In Russia, some research institutes have already mastered the methods and are developing industrial technology to reproduce elite aspen clones. This technology for obtaining planting material is given great attention in many countries.

The experience of cultivating elite aspen clones using the in vitro method suggests that this method is promising for use in forestry. This method can propagate not only aspen but also other fast-growing tree species. Aspen grown in vitro grows twice as fast as usual and is more resistant to fungal diseases [9-12]. In this regard, the formation of productive and stable aspen biogeocenoses becomes urgent.

This study aims to analyze the growth of aspen obtained by the in vitro method in the conditions of the Republic of Tatarstan.

\section{Research methods}

Aspen growth analysis studies were conducted from 2007 to 2020 . Two aspen genotypes were used in work clones No. 34 and No. 35, grown in the tremuletum of the Kostroma VOC, which were distinguished by their resistance to heart rot. Shoots were harvested from these clones to obtain healthy planting material. The selected clones were characterized by different ploidy: clone No. 34 has a diploid genotype (f2), clone No. 35 has a triploid genotype (f11). Growing of regenerants of both aspen genotypes was carried out on the nutrient medium of Murasig and Skoog with the addition of exogenous growth stimulants - $\alpha$-naphthylacetic acid at a concentration of $0.02 \mathrm{mg} / \mathrm{l}$ and 6-benzylaminopurine at a concentration of $0.5 \mathrm{mg} / \mathrm{l}$ when introduced into the culture and $0.1 \mathrm{mg} / \mathrm{l}$ with further micro-cutting. An important step in micropropagation is sterilization, which is carried out with whiteness. After that, the renal meristem was prepared for introduction into the culture by removing the renal scales and leaflets adjacent to the meristem. Then the finished explant was introduced into the culture. Flasks with plant material were placed in

\footnotetext{
Corresponding author: guzel-petrva@ rambler.ru
} 
lightroom, where the conditions of round-the-clock illumination were observed at an intensity of 1250 lux and a temperature of $23{ }^{\circ} \mathrm{C}$. Under these conditions, aspen micro shoots were formed, which were further propagated by micro-cutting.

The propagated microscopic cuttings were rooted by adding $\beta$-indolyl-3-butyric acid to the nutrient medium at a concentration of $2 \mathrm{mg} / \mathrm{l}$. Within one month, the transplanted microscopic cuttings were grown in lightroom under the same light and temperature conditions. During this time, they grew and took root. The test tube plants formed in this way were transplanted for further acclimatization in a greenhouse, where all the necessary conditions were created - watering, feeding, comfortable air humidity, as well as appropriate agrotechnical care. Half of the plants grown in a test tube were transplanted directly into the soil, and the other half were transplanted into pick bags (Fig. 1). Plant feeding was carried out daily with mineral fertilizer "Kemira Lux" with the addition of chalk or lime.
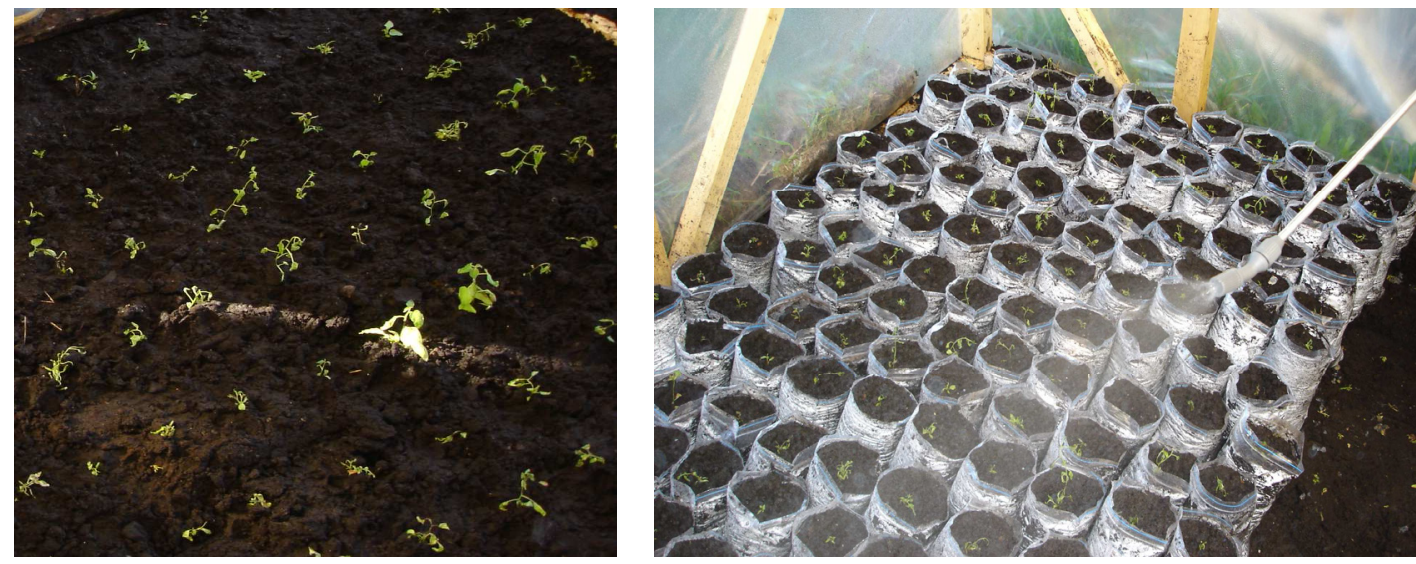

Fig. 1. Regenerant plants transplanted into the greenhouse and picking bags

\section{Results}

The formation of microshoots on the primary explant occurred within 30 days. According to our observations, the meristem of the triploid aspen began to grow on the fifth day after its introduction into the culture. In contrast, the meristem of the diploid aspen began to grow two days later. These data indicate that clone No. 35 is characterized by a greater morphogenetic potential compared to clone No. 34. Within one month of cultivation, microshoots of triploid forms reached a height of $3 \mathrm{~cm}$, and diploid ones - only $1 \mathrm{~cm}$. The presence of a significant difference between the compared forms in terms of kidney survival and shoot formation was proved using Student's test $(t=5.1>3)$.

The formed microshoots of aspen were cuttings and transplanted onto a fresh nutrient medium containing a root formation stimulator. For 40-45 days, the formation of plants with a developed root system took place (Fig. 2). Microshoots of triploid aspen were distinguished by more intensive growth as compared to diploid plants; accordingly, there were more microscopes from such forms.

According to the study results, it was noted that regenerants of triploid aspens had a shoot height three times higher than diploid forms. There was also a significant difference in the development of the root system between these forms. Thus, the number of plants with a formed root system in triploid aspens was almost $20 \%$ higher than in diploid ones. Table 1 presents data on the average height and number of plants with formed roots.

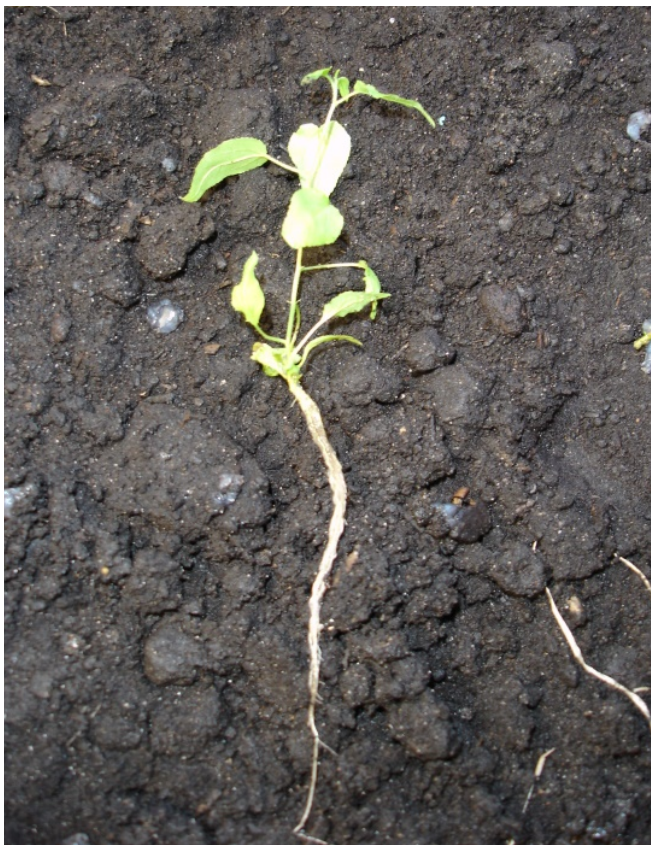

Fig. 2. Aspen sprout, clone no. 35

Table 1. Growth indices of diploid and triploid aspen regenerants

\begin{tabular}{|c|c|c|}
\hline Genotype & $\begin{array}{c}\text { Average } \\
\text { height }(\mathbf{H}), \mathbf{c m}\end{array}$ & $\begin{array}{c}\text { Number of plants } \\
\text { with roots, \% }\end{array}$ \\
\hline Clone No.34 (f2) & $1.5 \pm 0,4$ & $76.0 \pm 0,2$ \\
\hline Clone No. 35 (f11) & $3.7 \pm 0,2$ & $95.0 \pm 0,3$ \\
\hline
\end{tabular}

The calculated Student's test $(\mathrm{t})$ showed a significant difference in the height of test-tube plants $(t=5>3)$ and in the number of plants with roots $(t=52.3>3)$. Based on the data in Table 1, a diagram was compiled, 
reflecting a comparative analysis of the growth of regenerants of diploid and triploid forms of aspen before planting in the greenhouse (Fig. 3).

\section{Comparative analysis of the growth of regenerants of diploid and} triploid aspen clones before planting in the greenhouse

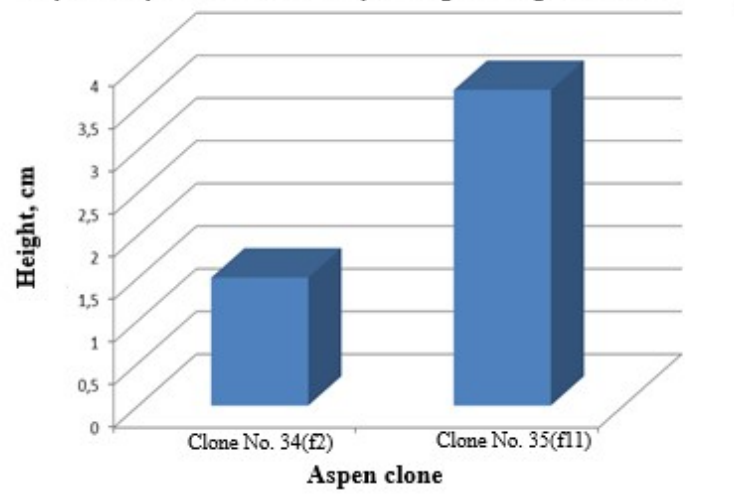

Fig.3. Results of biometric analysis of the height of diploid and triploid regenerants

For the further adaptation of test-tube plants to external conditions, they were transplanted into a greenhouse. According to our observations, the survival rate of test-tube plants was influenced by the time of their transplantation. The most favorable time was the period - spring or early summer. On average, plant survival under in vivo conditions was about $50 \%$. On the other hand, weather conditions had an adverse effect on the adaptation process of regenerated plants - after planting, there was a high air temperature (Fig. 4).



Fig. 4. Aspen seedlings ready for transplanting to the forest area

When studying the effect of the substrate on the growth and survival of aspen regenerant plants, the experiment showed that all tested substrates are suitable for growing aspen seedlings. However, the effectiveness of the substrates was different. The best survival rate was found on substrate No. 2 - soil + soddy soil + sand (1: 1: 1), slightly less - No. 3 - soil, and No. 1 - soil + sand (1: 1).

Table 2 shows the results of a statistical analysis of biometric indicators of aspen regenerants.

Studies have shown that the success of the adaptation of regenerant plants to external conditions is influenced by the following factors: plant genotype, the height of regenerants, length of the root system, planting time, method of transferring regenerants from test tubes to the substrate, quality of the substrate [14-16]. It was found that aspens with a triploid genotype had a better adaptive ability $(65 \%)$ than aspens with a diploid genotype $(30 \%)$. At the same time, triploid forms had a shoot height two times higher than diploid forms.

Table 2. Statistical analysis of biometric indicators of aspen regenerant plants

\begin{tabular}{|c|c|c|}
\hline \multirow{2}{*}{} & \multicolumn{2}{|c|}{ Genotypic forms of aspen } \\
\cline { 2 - 4 } & \multicolumn{3}{|c|}{ diploid } & triploid \\
\hline \multicolumn{3}{|c|}{ height, cm } \\
\hline $\mathrm{H}$ & 1.8 & 3.9 \\
\hline$\sigma$ & 0.6 & 1 \\
\hline $\mathrm{m}_{\mathrm{x}}$ & 0.02 & 0.05 \\
\hline $\mathrm{P}, \%$ & 1.1 & 1.3 \\
\hline $\mathrm{V}, \%$ & 31 & 25.6 \\
\hline \multicolumn{3}{|c|}{ root length, cm } \\
\hline $\mathrm{H}$ & 2.7 & 4.2 \\
\hline$\sigma$ & 0.6 & 1 \\
\hline $\mathrm{m}_{\mathrm{x}}$ & 0.03 & 0.06 \\
\hline $\mathrm{P}, \%$ & 1.1 & 1.4 \\
\hline $\mathrm{V}, \%$ & 20.1 & 23.8 \\
\hline
\end{tabular}

The aspen plants adapted to the external conditions were transferred to the silvicultural area. For this, the first aspen mother plantation was created on the territory of the Dendrological Garden of the State Institution "Sabinskoye Lesnichestvo" (Fig. 5). All the planted aspen seedlings took root. Biometric indicators of diploid and triploid forms of aspen are annually recorded: the height and diameter of each tree are measured.



Fig. 5. Triploid aspen mother plantation (2020)

Figure 6 shows the dynamics of growth of the studied genotypes.

Throughout the entire study period, starting from the moment of planting in 2007, the average height of triploid clones is on average two times higher than the diploid genotypes. Differences according to Student's test $(\mathrm{t})$ are significant. At the age of 12 years, the height 
and diameter of the triploid clone are 1.2 and 1.7 times, respectively, the diploid one prevails. This process led to an increase in the average volume of the trunk by three times (Fig. 7) [17, 18].

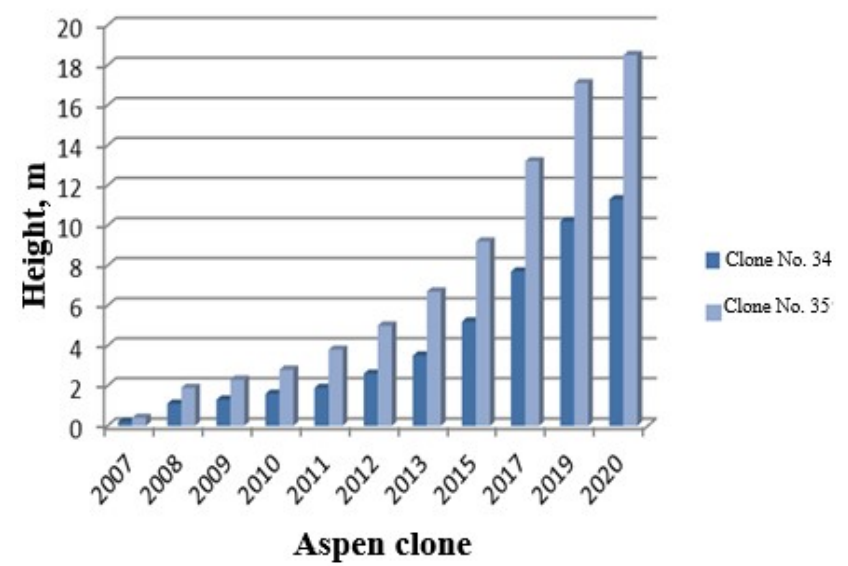

Fig. 6. Comparative dynamics of growth of heteroploid aspen clones for the period from 2007 to 2020

The growth rate of aspen trees and their resistance to heart rot are related. Fast-growing forms of aspen are the most rot-resistant $[4,13]$. Fruiting bodies of tinder fungi of the false aspen tinder fungus Phellinus tremulae Bond (Bond et Boriss) were not found on aspen trunks.

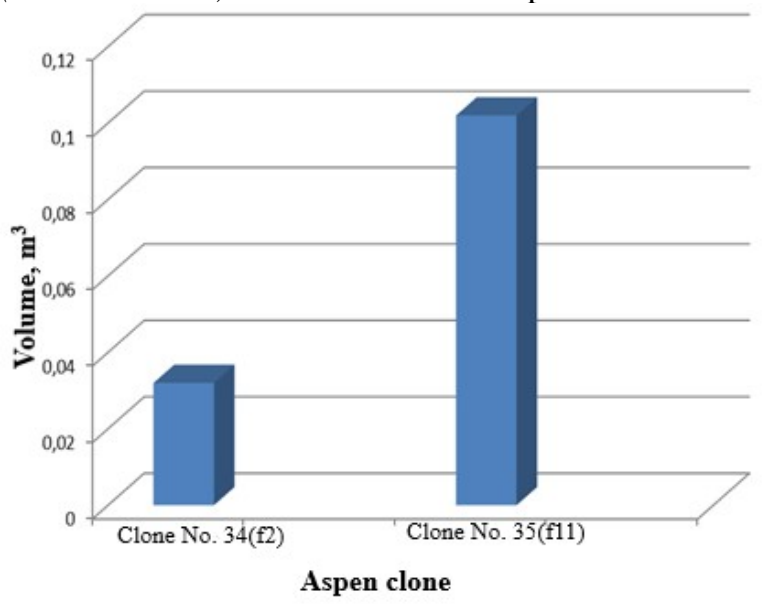

Fig. 7. The volume of wood of diploid and triploid aspen at the age of 12 years

The different growth rates of various aspen forms and their resistance to rot primarily depend on the individual characteristics inherent in these forms. Therefore, it is important to preserve and continue reproducing the valuable gene pool of triploid aspen clones.

\section{Conclusion}

Micropropagation methods make it possible to obtain the required amount of planting material for aspen clones resistant to pith rot. In the Republic of Tatarstan conditions, a clone with a triploid genotype turned out to be the most promising. In continuation of these studies in the republic, a selection of highly productive, rotresistant aspen genotypes was carried out in the republic's forests, followed by laboratory molecular genetic identification of triploids and experimental plantations of fast-growing tree species were established [10].

\section{References}

1. M.V. Lebedeva, E.A. Levkoev, V.A. Volkov, A.A. Fetisova, S.V. Navalikhin, D.A. Shabunin, Yu.I. Danilov, A.V. Zhigunov, E.K. Potokina, Experience in restoring the lost breeding achievements of Populus $\times$ leningradensis Bogd. and Populus $\times$ newensis Bogd. based on microsatellite analysis, Genet., 52(10), 1159-1168 (2016)

2. O.S. Alexandrov, G.I. Karlov, Development of Populus alba L. and Populus tremula L. Speciesspecific molecular markers based on non-transcribed 5S rDNA spacer polymorphism, Forests, 10(12), 1092 (2019)

3. A.S. Yablokov, Education and breeding of healthy aspen (Goslesbumizdat, Moscow, 1963)

4. A.S. Yablokov, The gigantic form of aspen in the forests of the USSR, Trudy VNIILKh (VNIILKh, Moscow, 1941)

5. A.I. Sivolapov, A.I. Chernodubov, V.A. Sivolapov, Experimental poplar cultures in felling areas of the educational experimental forestry enterprise VGLTA, Forest J., 1, 33-37 (2013)

6. O.S. Mashkina, E.A. Shabanova, I.N. Varivodina, T.A. Grodetskaya, Field trials of in vitro propagated clones of aspen (Populus tremula L.): growth, productivity, wood quality, genetic stability, Forest J., 6, 25-38 (2019)

7. M.M. Campbell, A.M. Brunner, H.M. Jones, S.H. Strauss, Forestry's fertile crescent: the application of biotechnology to forest trees, Plant Biotechnol. J., 1, 141-154 (2003)

8. A.V. Zhigunov, D.A. Shabunin, O.Yu. Butenko, Forest plantations of triploid aspen created by in vitro planting material, Bull. of the Volga State Univ. of Technol., Ser. Les. Ecol. Nat. manag., 4(24), 21-30 (2014)

9. N.A. Bovicheva, D.A. Shabunin, A.V. Zhigunov, V.A. Podolskaya, Growing triploid aspen seedlings from regenerants obtained by in vitro technology, Proc. of the St. Petersburg Res. Inst. of Forestry, 3(16), 68-76 (2006)

10. G.A. Petrova, E.A. Kalashnikova, Application of methods of cellular biotechnology for the conservation of biodiversity of aspen (Populus Tremula L.), Bull. of Kazan State Agrar. Univ., 3(1(7)), 147-150 (2008)

11. R. Schulzke, Die Anwendng on vitro kultutehniken bei Waldbanmen, Osterr Fortzfg, 99(3), 66-67 (1988)

12. A.V. Zhigunov, Application of biotechnology in forestry in Russia, Forest J., 2, 40-45 (2013) 
13. S.N. Bagaev, I.A. Korenev, S.S. Bagaev, D.N. Umbrella, Features of the formation of fastgrowing clones in the genetic reserve of a giant aspen, Forestry, 2, 26-28 (2013)

14. O. Malyuta, T. Gordeeva, N. Yatmanova, Nontraditional fertilizers as soil ameliorants: the study of usefulness, BIO Web of Conf., 17 (2020)

15. A.R. Muhametshina, R.Kh. Gafiyatov, L.P. Pukhacheva, Sh.Sh. Shaikhraziev, A. Akhmetov, The results of pre-sowing conifer seeds treatment by growth stimulators, BIO Web Conferences, 17, 5 (2020)
16. R. Gibadullin, A. Gubeidullina, V. Vinogradov, S. Glushko, G. Petrova, The dioxin regulation criteria in the agro-industrial complex of Russia, BIO Web Conferences, 17, 13-14 (2020)

17. K. Ulrich, D. Ewald, Breeding Triploid Aspen and Poplar Clones for Biomass Production, Silvae Genetica, 63(1-6), 47-58 (2014)

18. A. Tullus, L. Rytter, T. Tullus, M. Weih, H. Tullus, Short-Rotation Forestry with Hybrid Aspen (Populus tremula L. $\times$ P. tremuloides Michx.) in Northern Europe, Scand. J. of Forest Res., 27(1), 10-29 (2012) 